\title{
Diretrizes para processo de projeto de fachadas com painéis pré-fabricados de concreto em ambiente BIM
}

\author{
Guidelines for façade design process using precast \\ concrete panels in a BIM environment
}

\section{Luciana de Cresce El Debs Sérgio Leal Ferreira}

\section{Resumo \\ $\mathbf{E}$}

ste artigo expõe as diretrizes para a criação de um processo de elaboração de projetos que utilizam painéis pré-fabricados de fachada, tendo como base o ambiente de Building Information Modeling (BIM). Os painéis pré-fabricados arquitetônicos de concreto (PPAC) foram utilizados como ponto de partida para a estruturação da proposta. A lógica de montagem justifica esta abordagem: assim como no sistema construtivo préfabricado, em que as peças são construídas fora do canteiro e chegam a este no momento da montagem, em BIM, os componentes da indústria da Arquitetura, Engenharia e Construção (AEC) são modelados independentemente e inseridos no momento oportuno no modelo. Foram realizados estudos teóricos sobre as características dos PPACs, seguidos de consulta a profissionais experientes do setor, para confirmação da seleção de dados e procedimentos necessários para o projeto. Em seguida, elaboraram-se fluxogramas de orientação para o processo de projeto. Uma simulação do procedimento proposto foi feita com o programa Revit 2013, para validação. A proposta procura auxiliar o projetista a definir os passos de projeto, bem como os dados para a modelagem dos elementos. Ao auxiliar projetistas a conceber projetos utilizando elementos pré-fabricados, procura-se facilitar e estimular seu uso mais frequente no país.

Palavras-chave: BIM. Projeto. Painéis pré-fabricados. Painéis arquitetônicos.

\section{Abstract}

This paper presents guidelines for the development of a design process for projects using precast façade panels, within a Building Information Modelling (BIM) environment. Precast concrete architectural panels (PCAP) were chosen as the starting point for structuring the proposal. The assembly logic justifies this approach: just as in the precast building system where the pieces are manufactured away from the construction site and are brought to it at the time of installation, in BIM, the elements and components of the Architectural, Engineering and Construction (AEC) industry are independently modelled and added to the model as and when required. Theoretical studies about the characteristics of PCAPs were conducted. That was followed by consultations with experienced professionals in the field to confirm the data selection and the necessary procedures for the design. Thereafter, flowcharts were made to guide the design process. A simulation of the new procedures was performed using the Revit 2013 software for validation. The proposal seeks to aid designers to define the necessary design steps, as well as the data used for modelling the elements. Helping designers to conceive designs using precast elements should stimulate and facilitate the use of precast components in Brazil.

Recebido em 31/07/13 Aceito em 03/04/14
Keywords: BIM. Design. Precast panels. Architectural panels. 


\section{Introdução}

Elementos pré-fabricados são utilizados frequentemente na construção civil em países desenvolvidos, desde a metade do século XX. Sua aplicação na construção de edificações após as guerras mundiais contribuiu para a diminuição do déficit habitacional no continente europeu (ORDONÉZ, 1974). A pré-fabricação pode ser entendida como uma fase da industrialização, já que ainda não segue completamente todos os conceitos de produção e organização em série (BRUNA, 2002).

Em relação à industrialização da construção, Bruna (2002) indica que existem dois grandes ciclos de produção. O primeiro é o chamado ciclo fechado, que vigorou entre o pós-guerra e o final da década de 1960 , e representa a execução de uma obra por meio de uma única empresa ou de empresas coligadas. Após a década de 1960, dá-se início ao ciclo aberto, que também é chamado de "industrialização de catálogo", em que diversas empresas participam da fabricação de componentes para uma mesma edificação. Nesta produção é interessante a disponibilização de informações sobre os componentes industrializados, para que os projetistas possam especificar peças compatíveis de fabricantes diversos. Para isso, no contexto da habitação, foi necessária a divisão da célula habitacional em componentes elementares (BRUNA, 2002), ideia de subdivisão associada neste trabalho à montagem de um projeto com conceito de Building Information Modeling (BIM), tratado mais adiante.

Apesar de existentes há mais de meio século, a utilização de elementos pré-fabricados no país continua pequena em relação ao todo do mercado da construção civil nacional. Em países como os Estados Unidos e Canadá, além de países europeus, o painel arquitetônico pré-fabricado de concreto, objeto deste estudo, é vastamente utilizado (ARANTES, 2009).

Entre as razões para que o uso de inovações tecnológicas, como a utilização da pré-fabricação, seja pequeno na construção civil brasileira está a falta de conhecimento em sistemas e técnicas construtivas (SABBATINI; OLIVEIRA; MELHADO, 2001). No caso específico do painel de fachada, indicam-se como entraves a uma maior utilização: o custo inicial mais elevado em relação ao assentamento de blocos; a falta de conhecimento sobre a técnica; a falta de profissionais habilitados; e a necessidade de maior rigor dimensional da estrutura (SABBATINI; OLIVEIRA; MELHADO, 2001; ARANTES, 2009).
Os painéis pré-fabricados arquitetônicos de concreto (PPAC) para fachadas são adotados no país para, principalmente, obras em que se deseje ou necessite menor prazo de construção, já que grandes panos de fachada podem ser realizados com a instalação de poucos painéis. Sua fabricação externa à obra diminui a necessidade de estoque de material no canteiro e permite maior controle de qualidade durante a execução. Quando essa solução é adotada nos projetos no país, geralmente se trata de uma decisão tardia, com o projeto já em andamento. Isso implica retrabalho e nem sempre possibilita que o elemento pré-fabricado tenha todas as suas qualidades aproveitadas ao máximo (EL DEBS, 2000).

A fabricação dos componentes nesse tipo de sistema é feita exclusivamente através dos projetos detalhados, que permitem pouca improvisação no momento da instalação. Em geral, são utilizadas tolerâncias de montagem mínimas, e a obra deve ser executada dentro de desvios aceitáveis. Para tanto, é de essencial importância que o projeto arquitetônico e o de produção, principalmente, estejam bem resolvidos entre si e em relação às demais disciplinas.

$\mathrm{Na}$ área de projeto, um dos conceitos que está ganhando destaque é o de Building Information Modeling (BIM). Este aparece estimulando um novo processo, que permite a elaboração de um projeto que contenha informações sobre todo o ciclo de vida de uma construção (EASTMAN et al., 2011). Neste estudo, BIM é considerado um processo que resulta em um modelo composto de um conjunto de objetos, que se relacionam mediante regras e possuem, além de dados geométricos tridimensionais, dados não geométricos, que contribuem para uma definição mais completa dos objetos do modelo.

Estudos sobre esse tema iniciaram-se na década de 1970 e evoluíram junto com estudos sobre o paradigma computacional da orientação a objetos e a modelagem tridimensional aliada à modelagem paramétrica. Estes últimos foram desenvolvidos desde a década de 1980 para a indústria de manufatura e incorporados gradualmente ao projeto de edificações. A parametrização permite a criação de regras para a determinação da geometria ou para dados não geométricos dos elementos (EASTMAN et al., 2011). As regras são utilizadas de modo a permitir maior controle sobre o modelo, principalmente em casos de projetos complexos. Smith e Tardiff (2009) indicam também que esse tipo de modelagem aproxima-se da realidade da indústria da arquitetura, engenharia e construção. 
Entre as principais características de um modelo BIM estão a geometria tridimensional, a modelagem paramétrica e o armazenamento de dados geométricos e não geométricos (EASTMAN et al., 2011). Além dessas características, o BIM prevê a modelagem de objetos do mundo real (portas, janelas, paredes), e não a mera representação de objetos através de elementos bidimensionais ou mesmo tridimensionais, como linhas, curvas, paralelepípedos e esferas. O projeto pode ser conformado a partir de componentes préconfigurados, que utilizam parâmetros (locais ou globais) e restrições geométricas de localização e relação (em algumas implementações conhecidos como constraints) em sua constituição. Esses componentes são geralmente agrupados em bibliotecas de tipos de componentes da edificação e podem ser criados pelos projetistas e carregados nos projetos. Os grupos de componentes, por vezes, chamam-se "famílias", de forma semelhante a elementos fabricados em série; por exemplo: famílias de portas, de janelas, de louças, de metais, de elementos moldados no local (como as vedações) e de elementos pré-fabricados (como os sistemas de pele de vidro ou paredes-cortina). O modelo é gerado mediante a composição de instâncias desses componentes, o que permite uma espécie de montagem virtual da edificação. Desse modo, a criação de um protótipo virtual aproxima a construção civil das demais indústrias, como a aeronáutica, em que modelos são utilizados com frequência para a verificação do produto final antes de sua fabricação.

A possibilidade de acrescentar informações não geométricas ao modelo permite a criação de um banco de dados da edificação. Este facilita a organização das informações de um projeto de maneira lógica e consistente, para que ela seja acessível aos interessados no momento desejado (SMITH; TARDIF, 2009).

No exterior há alguns estudos sobre elementos préfabricados e a utilização do processo BIM. Entre eles podemos destacar os trabalhos de Kaner et al. (2008), Sacks et al. (2005), Eastman et al. (2008) e Jeong et al. (2009). Os dois últimos trabalhos referem-se a um grande estudo encomendado pela Fundação Charles Pankow, que teve como objeto de estudo os painéis pré-fabricados arquitetônicos de concreto.

Kaner et al. (2008) realizaram um estudo comparativo entre dois escritórios de engenharia que trabalham com elementos pré-fabricados, para avaliar a implantação do processo de BIM. Apesar de não entrar em detalhes sobre as especificidades desse tipo de construção, o artigo aborda as dificuldades dessa migração.
O trabalho de Sacks et al. (2005) consiste em um estudo realizado em diversos projetos, verificando os custos e benefícios da utilização do processo BIM. Além disso, foi realizado um estudo da modelagem 3D em comparação com a $2 \mathrm{D}$, para projeto com elementos pré-fabricados, verificando a produtividade alcançada em cada um.

Finalmente, o estudo encomendado pela Fundação Charles Pankow incluiu três grandes fases. A primeira fase, chamada de Rosewood Experiment, consistiu na modelagem de um edifício simultaneamente em 2D e em ferramenta BIM 3D. Após a modelagem do edifício como um todo, 10 peças pré-fabricadas foram selecionadas para ter seu detalhamento aprofundado. Esta primeira etapa procurou comparar a produtividade de ambos os processos (EASTMAN et al., 2008). A fase seguinte do estudo procurou estudar a interoperabilidade entre sistemas, comparando arquivos exportados de diferentes aplicativos BIM. No momento em que esse estudo foi realizado, a utilização dos modelos exportados para edição em outros aplicativos não foi satisfatória (EASTMAN et al., 2008; JEONG et al., 2009). Finalmente, a terceira etapa do estudo teve como objetivo a elaboração de um Information Delivery Manual, que contivesse os elementos necessários para a troca de informações geradas em diferentes tipos de contrato. Esse manual é específico para componentes pré-fabricados de concreto arquitetônico (EASTMAN et al., 2008).

Verificando a similaridade entre a o uso da chamada "industrialização de catálogo" e a "montagem virtual", propiciada pelo BIM devido à existência de elementos pré-configurados, juntamente com a modelagem paramétrica, propõe-se o estabelecimento de um processo de projeto que leve em conta características relevantes do objeto PPAC. Esse processo de projeto tem como objetivo sistematizar informações para o estabelecimento de uma ferramenta computacional de auxílio ao projeto de fachadas com elementos pré-fabricados dentro de um ambiente BIM. Essa ferramenta deverá ser inserida dentro do modelador, de modo a ser o mais interativa possível, tendo como resultado a inserção do componente PPAC no modelo. Para a verificação do roteiro, o aplicativo Revit 2013 foi escolhido devido à familiaridade dos autores com ele. Essa verificação foi feita simulando as etapas do processo proposto utilizando o software. Apesar dessa escolha, o trabalho foi conduzido de forma que esse processo possa ser replicado para a criação da ferramenta em qualquer plataforma modeladora.

Ao final da verificação no ambiente do Revit, foi feita uma exportação para o formato IFC (Industry 
Foundation Classes), com o objetivo de verificar como esse modelo armazenaria as informações geradas pela ferramenta. Como essa verificação está fora do escopo deste artigo, uma vez que lida com a validação do tipo de modelo usado, enquanto este trabalho aborda o processo de projeto, optou-se por não apresentá-la. Para mais informações ver El Debs (2013). O IFC é um modelo proposto pelo esforço coletivo da entidade hoje chamada de buildingSMART, com o objetivo de conter os dados sobre o ciclo de vida de uma edificação e para a troca de informações entre os participantes do projeto (FERREIRA; KAWANO, 2006). Atualmente, o IFC é uma norma ISO (INTERNATIONAL..., 2013). O arquivo resultante da exportação serve como orientação para implementações em outras plataformas.

Este processo auxiliará a criação de uma ferramenta que funcionará dentro dos aplicativos modeladores, como um plug-in, pela qual os arquitetos e projetistas indicarão as informações necessárias ao projeto, e o produto desse processo será representado por objetos parametrizados (PPACs e insertos).

Uma das coisas que fazem a modelagem BIM ser muito interessante, e com grande potencial de desenvolvimento, é a capacidade que ela tem de manipular as informações com a sintaxe apropriada ao domínio da construção. Pensando na possibilidade de um aplicativo trabalhar com o PPAC dentro do ambiente BIM, procuraram-se os componentes que já existiam no modelo de dados, que, com algumas poucas informações adicionais, passariam a apresentar-se de modo compatível com o novo papel desempenhado. As ferramentas de edição e regras de validação permanecem as mesmas de qualquer outro componente. A ferramenta deverá acrescentar rotinas de verificação específica, para auxiliar ainda mais o projetista.

Para a realização da proposta, foi feita, primeiramente, uma abordagem teórica sobre os painéis pré-fabricados arquitetônicos de concreto. A partir desta, selecionaram-se algumas características consideradas importantes desse elemento, para que fossem avaliadas, posteriormente, por alguns profissionais da área, mediante entrevistas. Após esse processo de avaliação, foram realizados os ajustes necessários nas características selecionadas e criados fluxogramas de orientação para o processo de projeto. Os fluxogramas representam a sequência de utilização que se pretende para a ferramenta, bem como a definição dos campos disponíveis para seleção e edição pelos projetistas.
Finalmente, faz-se um balanço sobre as dificuldades encontradas e características incorporadas dentro do processo em relação ao conceito de modelagem da informação da construção. Destaca-se a possibilidade de utilização desse roteiro para aumentar o conhecimento sobre os PPAC e para diminuir a resistência relacionada a sua utilização.

\section{Seleção de características a partir do estudo teórico}

Para este estudo, os painéis pré-fabricados arquitetônicos de concreto foram delimitados de acordo com as seguintes características:

(a) painéis de vedação (não estruturais);

(b) painéis maciços ou sanduíche;

(c) painéis com tela eletrossoldada;

(d) painéis com acabamento em concreto colorido, com texturas e/ou relevos; e

(e) painéis com ligações através de insertos metálicos.

A compreensão das características e do processo de projeto desses painéis realizou-se com base em três fontes principais: as dissertações de Oliveira (2002) e de Arantes (2009), e o manual para painéis arquitetônicos do Precast/Prestressed Concrete Institute, dos EUA (PRECAST; PRESTRESSED CONCRETO INSTITUTE, 2007).

Os painéis de concreto podem ser divididos em três componentes básicos: o painel; os dispositivos de fixação ou ligação (entre o painel e a estrutura principal); e as juntas (ARANTES, 2009; OLIVEIRA, 2002). A Figura 1 ilustra esses componentes.

Dentro do componente painel também é possível realizar uma subdivisão em três camadas, conforme apresentado na Figura 2:

(a) o concreto (com o reforço feito através de tela eletrossoldada ou com fibras, que é objeto do estudo);

(b) o revestimento (se houver); e

(c) o isolamento (se houver).

Os dispositivos de ligação, também chamados de insertos metálicos, podem ser classificados em três tipos: de gravidade, que servem à sustentação do painel; de contraventamento; e de alinhamento (ARANTES, 2009). Este último é facultativo, sendo utilizado em painéis mais alongados e em casos especiais. 
Figura 1 - Componentes do sistema PPAC

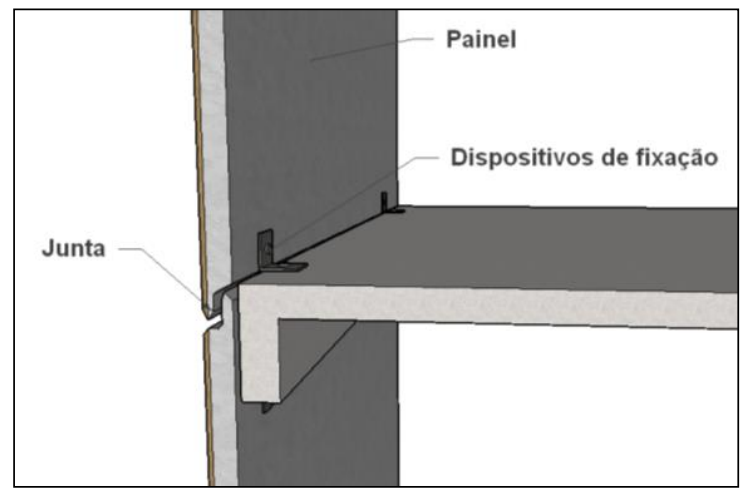

Figura 2 - Componentes do painel arquitetônico

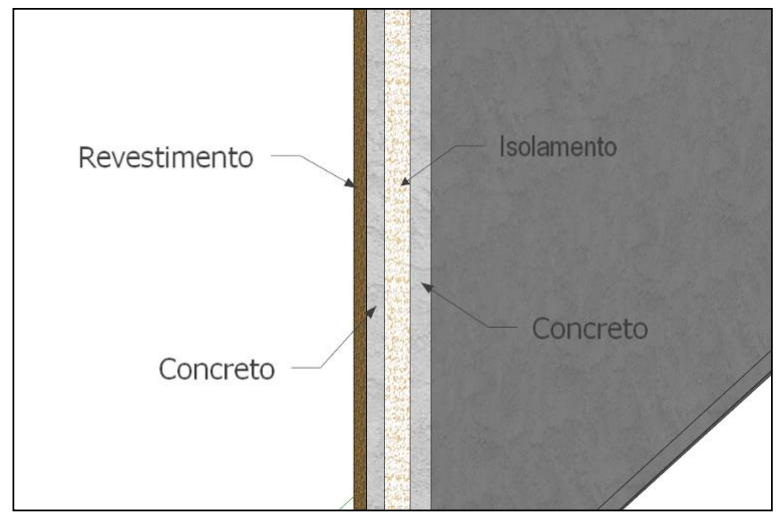

As juntas, que são caracterizadas como os espaços entre os painéis, também se distinguem em verticais e horizontais, e podem ser tratadas de diversas maneiras. A função das juntas é permitir a montagem dos painéis e também acomodar as variações dimensionais causadas pela alteração de temperatura, carregamento ou umidade (ARANTES, 2009). Além disso, podem existir juntas falsas, de acordo com a intenção desejada pelo arquiteto.

A partir do estudo teórico realizado sobre o sistema, verificam-se algumas características que devem ser levadas em consideração pelo projeto: dimensões, acabamento, materiais isolantes, insertos metálicos e juntas. Para mais detalhes sobre os parâmetros dessas características utilizados nos elementos, ver El Debs (2013), Arantes (2009) e Oliveira (2002). Tais características também serviram de subsídio para a elaboração de questionário a ser respondido por profissionais da área, com o objetivo de validação para o que foi selecionado durante o estudo teórico.

\section{Revisão e seleção das características com base nas entrevistas}

Para a melhor compreensão sobre a situação atual do mercado para painéis pré-fabricados arquitetônicos de concreto e também para confirmar se as características selecionadas através do estudo teórico eram as mais adequadas para a proposta, realizaram-se entrevistas com profissionais da área. Foram selecionados quatro entrevistados, que possuem experiência variada na fabricação ou no projeto de pré-fabricados.

As entrevistas foram feitas face a face, de forma semiestruturada, conforme as definições de Gil (2002) e Cervo e Bervian (1996), seguidas pelo preenchimento de formulário pelo entrevistado. A entrevista teve como objetivo conhecer mais sobre o processo de trabalho do profissional em relação a utilização de PPACs por ele. O formulário, por sua vez, foi dividido em três partes:
(a) a primeira sobre o perfil do entrevistado;
(b) a segunda sobre os conhecimentos do entrevistado acerca do conceito BIM; e 
(c) a terceira quanto aos aspectos relacionados aos PPACs e sobre a proposta de ferramenta.

É através da análise dos resultados desta última etapa que se procurou validar as características identificadas por meio dos estudos teóricos. O presente artigo apresenta os achados mais importantes da terceira parte do formulário aplicado.

Apresentou-se aos entrevistados uma relação de características identificadas como potenciais a serem abordadas pela ferramenta:

(a) dimensões;

(b) existência e especificação de isolamento (acústico ou térmico);

(c) cor do painel;

(d) textura do painel (lisa, áspera, desenhada...);

(e) localização das ligações/insertos metálicos;

(f) especificação das ligações/insertos metálicos;

(g) indicação do tipo de inserto/ligação (gravidade, alinhamento ou contraventamento);

(h) indicação de juntas falsas;

(i) largura das juntas verdadeiras; (j) indicação de juntas de um estágio ou dois estágios;

(k) detalhamento de quinas, evitando $90^{\circ}$;

(1) especificação da resistência do concreto a ser utilizado;

(m) indicação do peso do painel; e

(n) localização sugerida para as alças de içamento.

Com base na relação apresentada, solicitou-se aos entrevistados indicar as cinco características que achavam de maior importância ao desenvolvimento de uma ferramenta computacional para PPAC. Os resultados estão contidos no Quadro 1, a seguir, que apresenta as que obtiveram maior número de menções em ordem decrescente. Vê-se a grande importância dada às dimensões, localização de ligações e insertos metálicos, e definição das juntas.

$\mathrm{Na}$ terceira parte do formulário, também se perguntou aos profissionais sobre o que uma ferramenta com conceito BIM aplicada ao projeto de PPAC poderia fazer. O questionário trazia algumas opções, mas também deixava em aberto para mais sugestões. A Figura 3 apresenta os resultados.

\section{Quadro 1 - Características dos projetos para PPACs para fachadas}

\begin{tabular}{|l|l|}
\hline $1^{\circ}$ & Dimensões \\
\hline \multirow{2}{*}{$2^{\circ}$} & Localização das ligações/insertos metálicos \\
\cline { 2 - 3 } & Indicação das juntas de um estágio ou dois estágios \\
\hline \multirow{3}{*}{$3^{\circ}$} & Indicação de juntas falsas \\
\cline { 2 - 2 } & Largura das juntas verdadeiras \\
\cline { 2 - 2 } & Cor do painel \\
\hline \multirow{3}{*}{$4^{\circ}$} & Existência e especificação de isolamento (acústico ou térmico) \\
\cline { 2 - 2 } & Textura do painel (lisa, áspera, desenhada...) \\
\cline { 2 - 2 } & Detalhamento de quinas, evitando $90^{\circ}$ \\
\cline { 2 - 2 } & Indicação do peso do painel \\
\hline
\end{tabular}

Figura 3 - O que uma ferramenta com conceito BIM aplicada ao projeto de PPACs poderia fazer, segundo os entrevistados

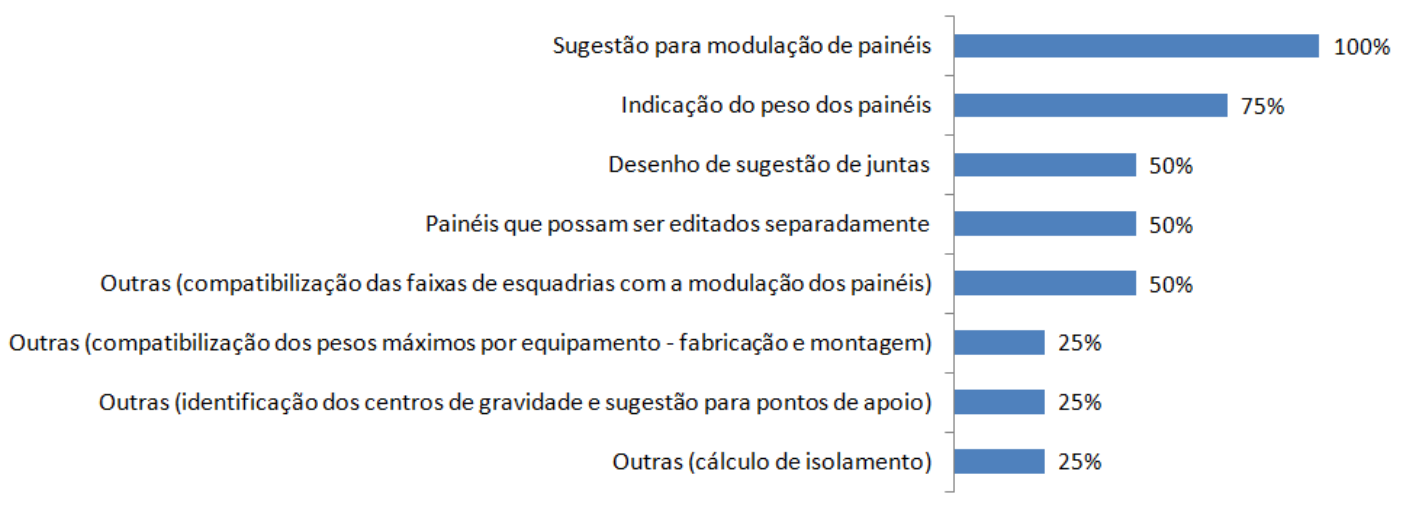

46 El Debs, L. de C.; Ferreira, S. L. 
Durante a entrevista foi mencionado o desconhecimento técnico por parte dos construtores, clientes ou projetistas como uma barreira a ser enfrentada para uma maior utilização de elementos pré-fabricados. Porém, a diminuição de custos com encargos na produção como forma de estimular sua difusão e a pesquisa, além da divulgação do assunto, são iniciativas consideradas bem-vindas para aumentar sua utilização, sendo uma alternativa ao uso de alvenarias ou fechamentos executados no local.

Com base no que foi estudado e nas entrevistas realizadas, definiram-se oito etapas de trabalho para o desenvolvimento do processo de projeto, definidas na relação a seguir. As fases abaixo representam a sequência de atividades no processo, porém, uma vez completas, é possível retornar para alterar alguma especificação:

(a) limitações de peso, comprimento e altura;

(b) isolamentos e espessura do painel;

(c) modulação;

(d) insertos metálicos;

(e) juntas verdadeiras;

(f) juntas falsas;

(g) acabamentos; e

(h) detalhes construtivos.

Essas oito etapas procuram abranger o maior número de características indicadas no questionário. Procurou-se dar prioridade às características indicadas como mais importantes.
Os resultados da Figura 1 balizaram os processos mais importantes, indicando que uma boa modulação é essencial ao desenvolvimento de projetos com elementos pré-fabricados do tipo PPAC. O processo proposto procurou desenvolver essa questão como principal, pois envolve as etapas 1 a 6 , das 8 indicadas acima. Também se procurou permitir a flexibilidade do projeto para atender ao maior número de tipos diferentes, visto que a variedade de acabamentos e formas dos PPACs é uma das vantagens desse tipo de elemento (ARANTES, 2009).

\section{Proposta do processo de projeto: fluxogramas e simulação}

Uma vez identificados os itens de trabalho, organizados conforme representa a Figura 4, estes foram desmembrados em subitens. As etapas foram organizadas em mais fluxogramas, que indicam as informações necessárias e as resultantes em cada uma delas. Desse modo, estrutura-se um roteiro sobre o processo de projeto necessário para o desenvolvimento de PPACs. Propõe-se que esse roteiro seja utilizado para o desenvolvimento de uma ferramenta computacional na sequência deste trabalho. Para tanto, o roteiro segue os passos para o desenvolvimento do projeto tendo em vista a utilização de um modelador BIM. Alguns fluxogramas estão apresentados neste artigo. Para o conteúdo completo destes ver El Debs (2013).

Figura 4 - Esquema geral do processo de projeto de elementos PPAC

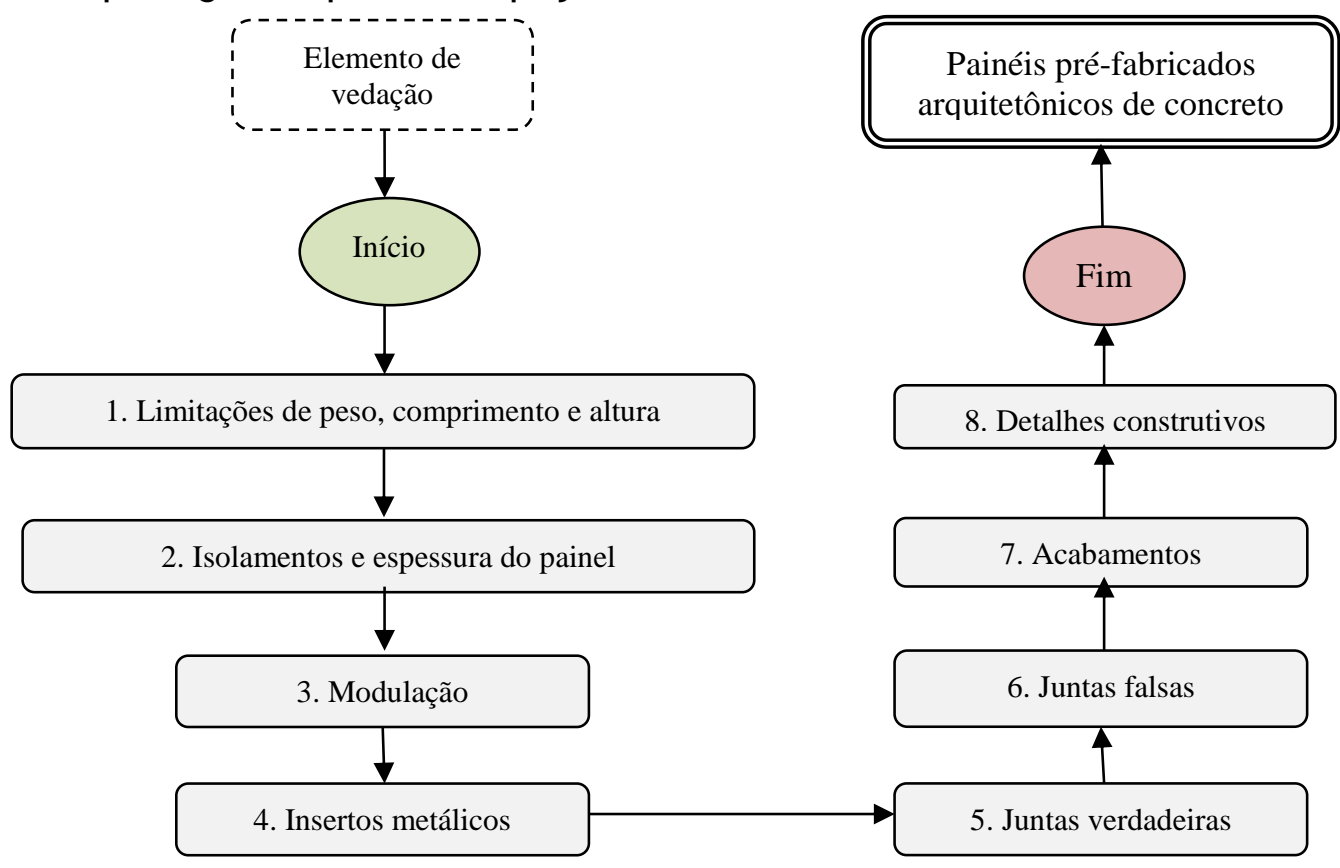


A primeira etapa do processo refere-se à definição de limitações de peso, comprimento e altura. Para essa etapa será necessária a especificação dos dados sobre os limites máximos impostos nas etapas de fabricação, transporte e montagem. Caso esses limites não sejam conhecidos, sugerem-se algumas dimensões máximas usuais de mercado e determinadas com base nos estudos teóricos feitos (ARANTES, 2009; OLIVEIRA, 2002).

A etapa seguinte do processo é a de especificação de isolamentos e espessura do painel. Esta etapa pode ser dividida em duas partes. A primeira trata da indicação de existência de materiais isolantes. Se estes existirem, é necessário especificá-los, bem como a espessura da camada. Nesse caso, é necessário prever o cadastro de alguns materiais, como o EPS e o XPS, e suas características principais, como transmitância térmica, capacidade térmica, isolação sonora e densidade. Sendo necessário cadastrar um novo material, isso deve ser possível indicando-se, no mínimo, sua densidade, para que seja possível o cálculo do peso final do painel.

Em seguida, parte-se para a definição da espessura total do painel. Neste caso, deve-se indicar a espessura mínima de $10 \mathrm{~cm}$ ou entre $1 / 50$ do comprimento, e máxima de $1 / 20$ do comprimento do painel. Essas dimensões baseiam-se nas informações obtidas pelos estudos teóricos. Deve ser possível também aceitar a sugestão para um painel básico, cuja espessura deverá ser de $10 \mathrm{~cm}$ ou 1/50 do comprimento do painel, adotando a maior medida entre as duas.

Com base nas informações fornecidas nas etapas 1 e 2, parte-se para a etapa de modulação. Nesta, a primeira informação a ser fornecida em relação à definição da geometria dos painéis de canto é relativa à junta-prumo, chanfro ou aba (conforme a Figura 5). Essa definição é importante, pois pode alterar a localização das linhas de modulação.

Ainda na etapa de modulação, representada pela Figura 6, apresentam-se algumas opções que permitem a modulação baseada no maior número de repetições e na maior dimensão dos painéis possível, escolhendo adotar a altura do painel igual à altura do andar, ou indicar o número de colunas ou linhas desejado. Além dessas opções, deve-se permitir um número predefinido de linhas e colunas, e ajustá-las no modelo criado para estudo, de acordo com o que se deseja para a fachada. Essas opções visam dar flexibilidade ao processo idealizado e aos modelos gerados.

Devido à alta complexidade da definição de modulação, propõe-se que os painéis gerados sejam editáveis individualmente. Isso visa dar ainda mais flexibilidade ao processo. Alerta-se, porém, que, dependendo da edição realizada, será necessário analisar novamente os pontos de apoio de carga, já que talvez seja necessário o deslocamento para acomodar a nova posição dos painéis. No ambiente BIM, será conveniente que essa verificação seja feita por uma rotina computacional, apoiando o trabalho de decisão do projetista e alertando sobre possíveis incoerências.

Com a modulação dos painéis concluída, parte-se para a etapa do processo relativa à definição dos insertos metálicos para a ligação entre os painéis e a estrutura principal do edifício. Para tanto, é necessária uma distinção entre insertos de alinhamento, que podem ou não ser utilizados, dependendo do comprimento ideal indicado inicialmente, e de contraventamento e gravidade.

Para estes últimos - insertos de contraventamento e gravidade - deve-se solicitar a indicação de definições para dois parâmetros. Primeiro, é necessário indicar a organização dos insertos dentro do painel, isto é, quais os insertos de gravidade serão inferiores e os de contraventamento superiores, ou o inverso. Em seguida, deve-se indicar a localização dos insertos em relação à estrutura do edifício, conforme as opções apresentadas na Figura 7.

Figura 5 - Proposta de geometria para os painéis de canto

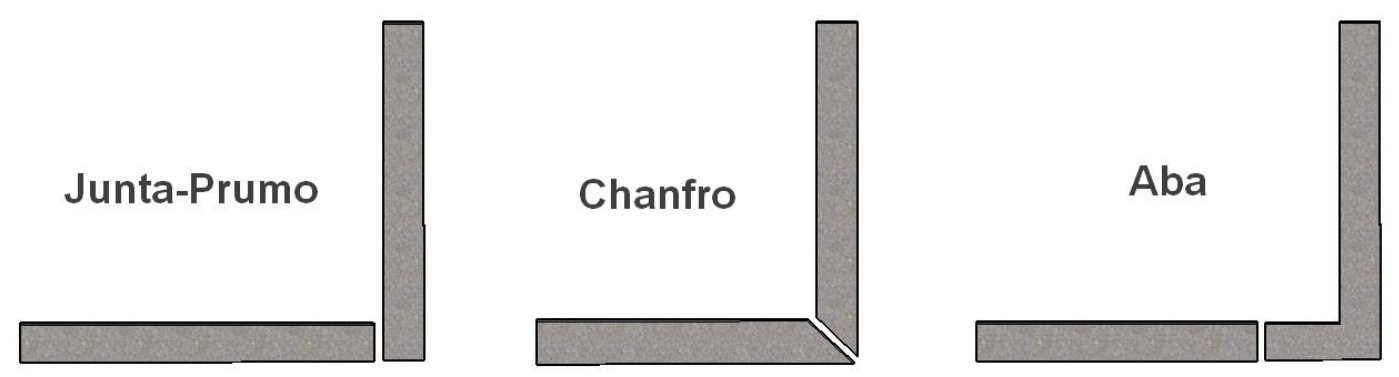

48 El Debs, L. de C.; Ferreira, S. L. 
Figura 6 - Modulação dos painéis - etapa 3.2

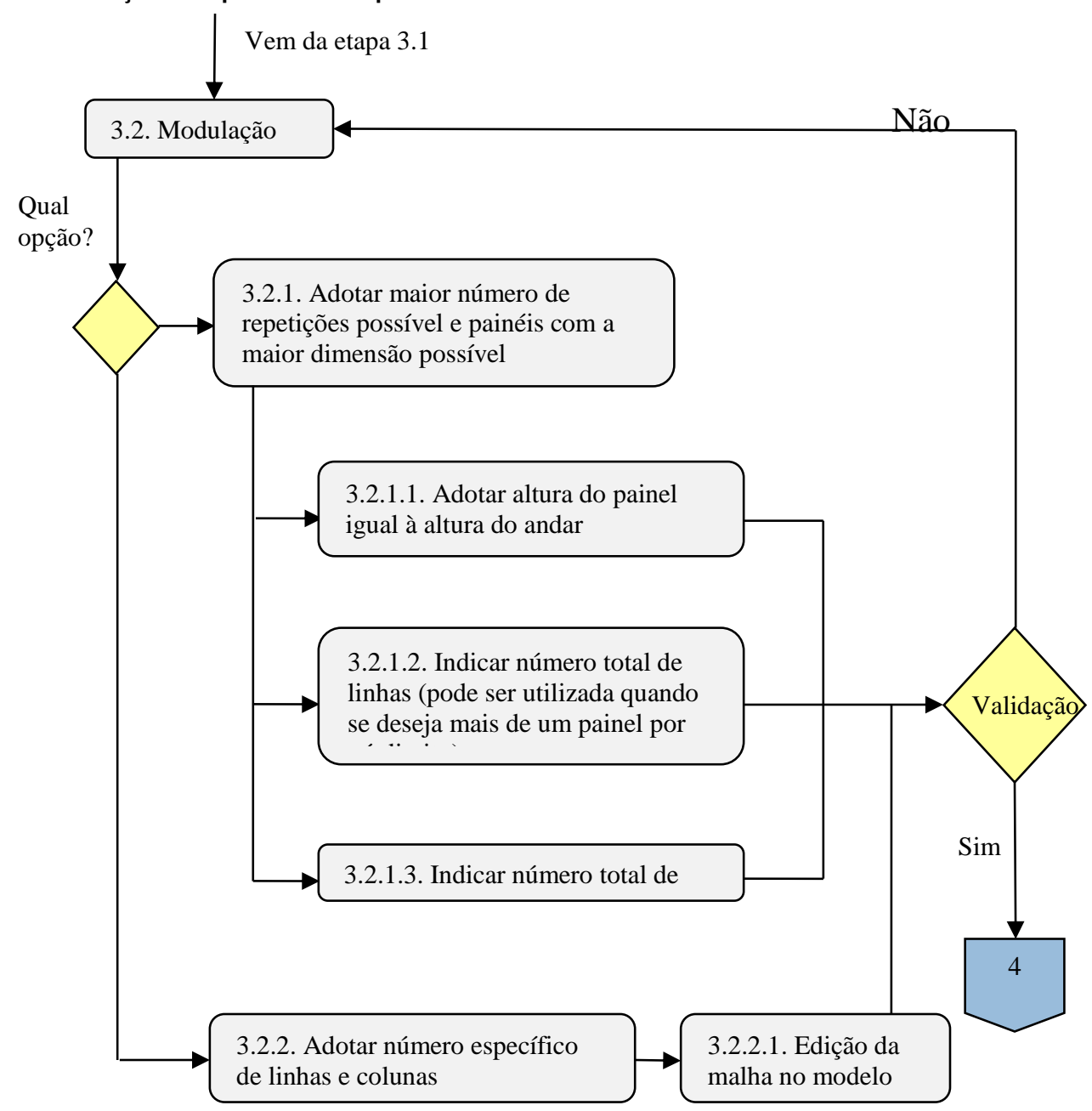

Figura 7 - Opções de localização dos insertos entre painel e estrutura principal
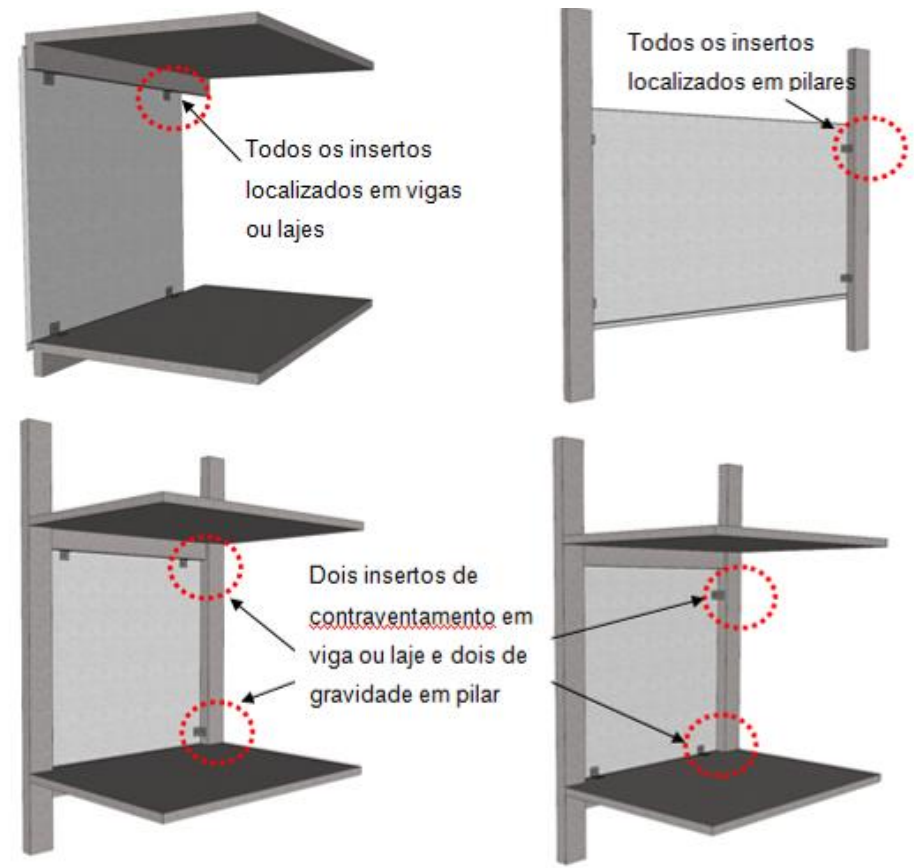
Ainda na etapa de projeto relativa à definição dos insertos, requer-se que seja indicado se os insertos serão aparafusados ou soldados e também a distância entre os painéis e a estrutura do edifício. Nesta etapa sugere-se a opção de proposição de uma medida predefinida, com base nos estudos teóricos de Arantes (2009) e Oliveira (2002).

$\mathrm{Na}$ etapa de definição dos insertos metálicos e das juntas verdadeiras, deve-se gerar uma prévia da localização dos elementos estruturais (vigas e pilares) necessários para a sustentação dos painéis. Sugere-se que sejam utilizadas dimensões padronizadas em 20x30 cm para esses elementos, que deverão ser substituídos pelos elementos estruturais calculados após a conclusão do processo, e seu posicionamento deverá ser ajustado. A localização desses elementos é gerada em função da distância mínima do centro destes (pilares e vigas) e o centro da junta proposta, conforme a Figura 8. Deverão ser tridimensionais, para facilitar a visualização do conjunto e permitir uma análise inicial do sistema de suporte aos painéis.

Seguindo para a etapa de definição das juntas verdadeiras, deve-se solicitar a indicação de algumas especificações, entre elas se as juntas serão de um ou dois estágios e se haverá ou não junta de drenagem na horizontal. Depois dessas definições, deve-se informar os parâmetros necessários ao cálculo da largura das juntas relativo ao selante a ser utilizado. Neste caso, são necessários os cadastrados dos dois selantes mais utilizados no país, segundo os estudos teóricos (os selantes de silicone de baixo e médio módulo). É possível realizar o cadastramento de um material diferente, desde que seja indicada sua capacidade de movimentação. Sugere-se, para tanto, a criação de um novo material dentro da biblioteca do aplicativo utilizado, em que é possível indicar as propriedades mecânicas necessárias.
Com base nessas informações e em outras a serem extraídas dos dados já inseridos (comprimento do maior painel), calcula-se a espessura mínima da junta com base na Equação 1, indicada a seguir, baseada em publicação do Precast e Prestressed Concrete Institute (2007). Deve-se permitir editar o campo da variação de temperatura, para melhor ajuste às condições do local da obra.

Largura mínima da junta $=(100 / \mathrm{A}) * \mathrm{~B}+\mathrm{C}$ Eq. 1 Onde:

A = capacidade de movimentação do selante;

$\mathrm{B}=$ deformação dos painéis devido à variação dimensional por diferença de temperatura adotada $10-5 \mathrm{~mm} / \mathrm{mm}^{\circ} \mathrm{C}$ x $30{ }^{\circ} \mathrm{C}$ x comprimento do maior painel; e

\section{$\mathrm{C}=$ tolerância $( \pm 6 \mathrm{~mm})$.}

A dimensão calculada deverá ficar entre o mínimo de $6,4 \mathrm{~mm}$ e o máximo de $50 \mathrm{~mm}$, conforme as recomendações encontradas nos estudos teóricos (DOW CORNING, 2005' apud ARANTES, 2009). Essa limitação leva em consideração as deformações dos painéis e a facilidade para a execução do preenchimento das juntas. É possível que o usuário edite a largura calculada, porém deverá respeitar o mínimo e o máximo indicados anteriormente.

Finaliza-se o processo de definição da junta verdadeira estabelecendo-se sua geometria com base em algumas opções do mercado. Sugere-se que a modelagem disso seja feita através de operação booleana de subtração, realizada no elemento painel criado anteriormente. Durante essa operação, um elemento tridimensional representando a geometria da junta é subtraído do elemento tridimensional que representa o painel arquitetônico.

\section{Figura 8 - Localização em planta da proposta dos pilares em relação às juntas dos painéis}

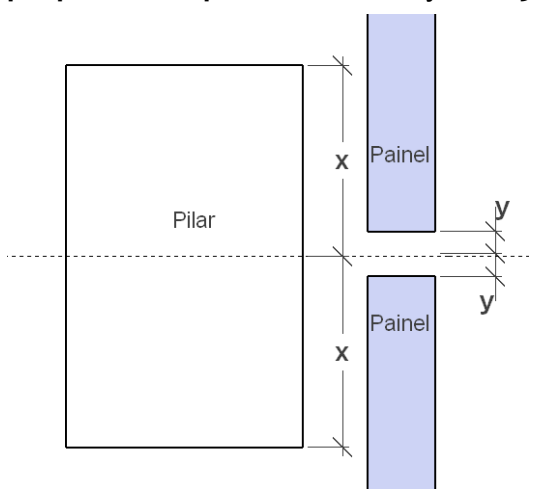

${ }^{1}$ DOW CORNING. Manual Técnico das Américas da Dow Corning. Janeiro, 2005. Disponível em:

<https://www.dowcorning.com.cn/zh_CN/content/publishedlit/62-1112e-11.pdf>. Acesso em: 16 jun. 2014. 
A etapa seguinte refere-se à definição de juntas falsas. Estas são opcionais e, caso não estejam no projeto, é possível passar diretamente à etapa seguinte. Caso elas existam, é necessário que se indique a geometria e espessura desejadas, podendo sempre optar ou não pelas mesmas adotadas para as juntas verdadeiras (etapa 5).

A penúltima etapa proposta para o processo de projeto de PPACs é relativa aos acabamentos possíveis para os painéis. Nesta etapa requer-se também a flexibilidade para escolher um acabamento para todos os painéis, ou múltiplos acabamentos (conforme a Figura 9).

Devem-se prever acabamentos sem tratamento, colorido (em que é possível indicar a cor desejada), ou texturizado (lavado ou jateado em três intensidades diferentes), os quais estão representadas pela Figura 10, e também duas opções personalizadas de desenho, cujos parâmetros estão contemplados na Figura 11.

Sobre as opções de desenho personalizado, deve-se possibilitar desenhar frisos nos painéis, diretamente no modelo, e permitir que uma figura seja utilizada para gerar um mapa de relevo a ser aplicado nos painéis. Esse relevo poderá ser alto ou baixo, com no máximo $20 \mathrm{~mm}$, para que evite quebras no caso de partes sobressalentes, ou que interfira com o reforço do painel.

Finalmente, a última etapa do processo de projeto para PPACs leva em consideração a existência ou não de acabamento de topo especial (em chanfro) e também a existência de peitoris. Ambos os detalhes visam melhorar o desempenho dos painéis em relação às manchas na superfície por água da chuva. No caso da existência de peitoris deve-se permitir selecionar um dos modelos préconfigurados que têm como base os estudos de Oliveira (2002), ou propor um novo modelo que se adapte melhor às necessidades do usuário.

Ao final desse processo tem-se como resultado todo o sistema de fachada (painéis, juntas e insertos metálicos), além de uma proposta para a demarcação para a pré-estrutura do edifício, agrupados.

Figura 9 - Seleção dos painéis para acabamento - etapa 7.1

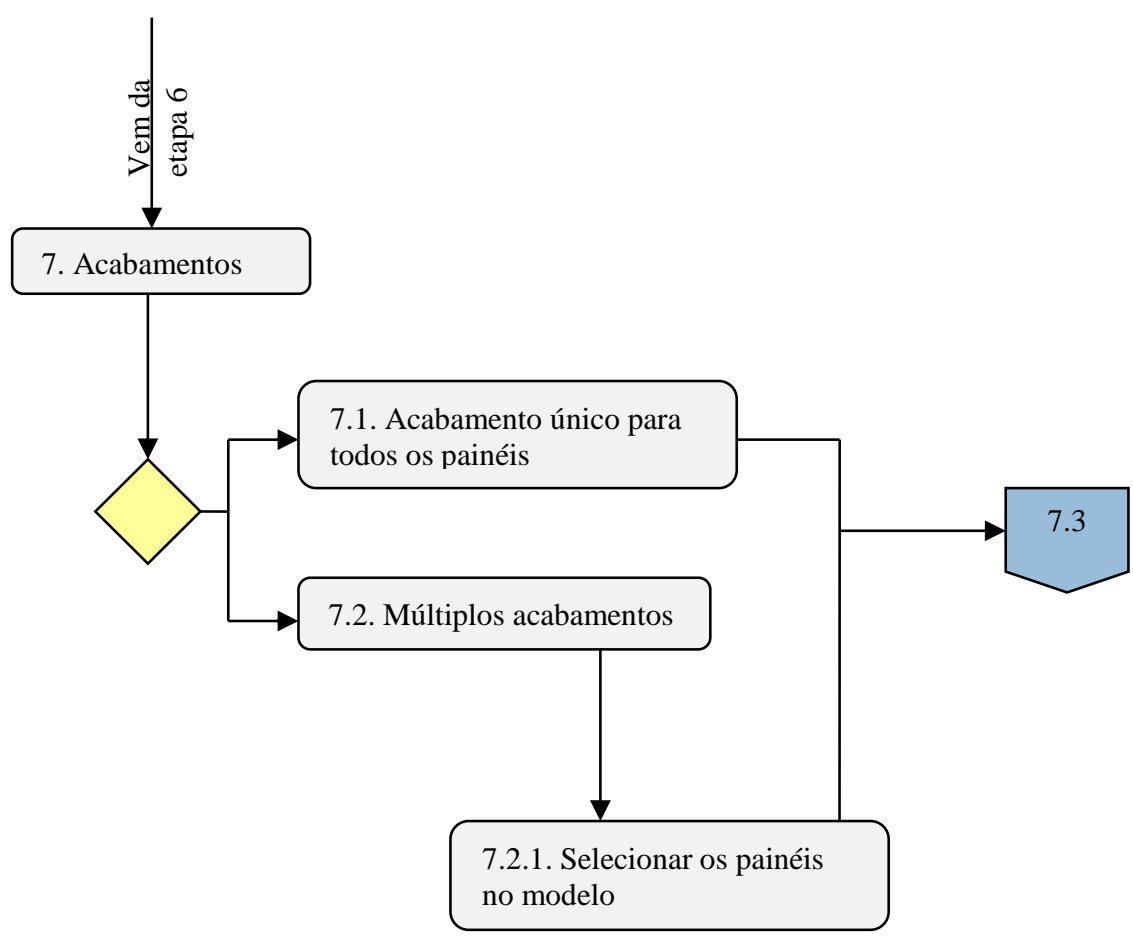


Figura 10 - Tipos de acabamento - etapas 7.3.1, 7.3.2 e 7.3.3

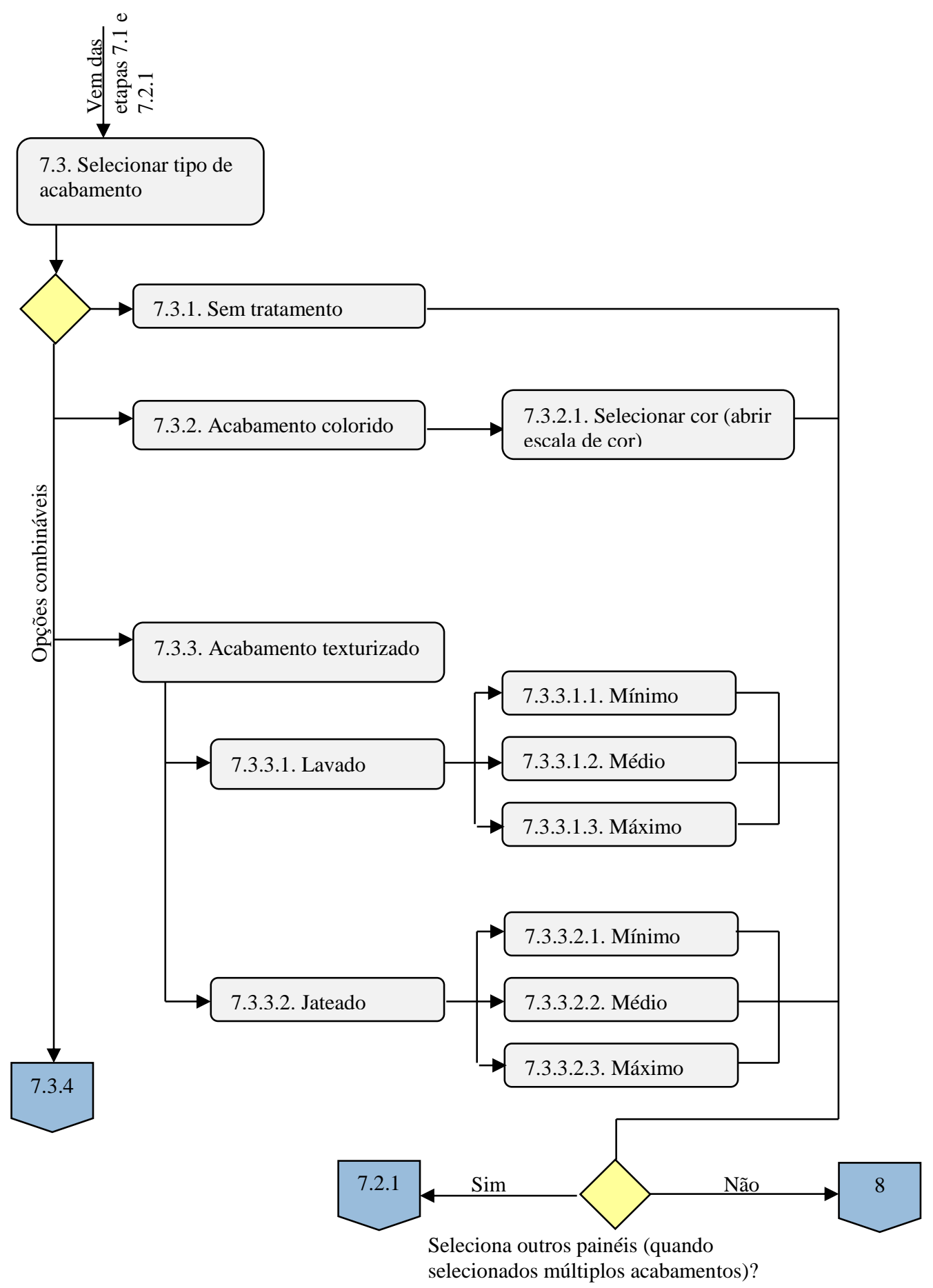

Após a definição da proposta de organização dos fluxos de informação, foi realizado um teste sobre a sequência dos itens, utilizando o projeto de um galpão no aplicativo Revit 2013 (Figura 12). Este teve como objetivo verificar o encadeamento lógico das etapas e a necessidade de ajustes, que foram realizados para o aperfeiçoamento dos fluxogramas e indicações apresentadas neste artigo.

Para o teste, utilizou-se o componente curtain wall. A fachada foi modelada de forma contínua, e depois as separações (que representam as juntas dos PPACs) foram adicionadas. A simulação utilizou-se das informações que foram inseridas 
nas etapas 1 e 2 do processo, portanto a avaliação destas é feita conjuntamente com a terceira, que é a primeira visualização do modelo. As linhas de modulação foram feitas com a ferramenta curtain grid. Através desta, foi possível visualizar e aprovar ou não a modulação proposta. A Figura 13 representa como essas linhas poderiam ser visualizadas (utilizando também linhas de grade para auxílio).

\section{Figura 11 - Desenhos personalizados - etapa 7.3.4}

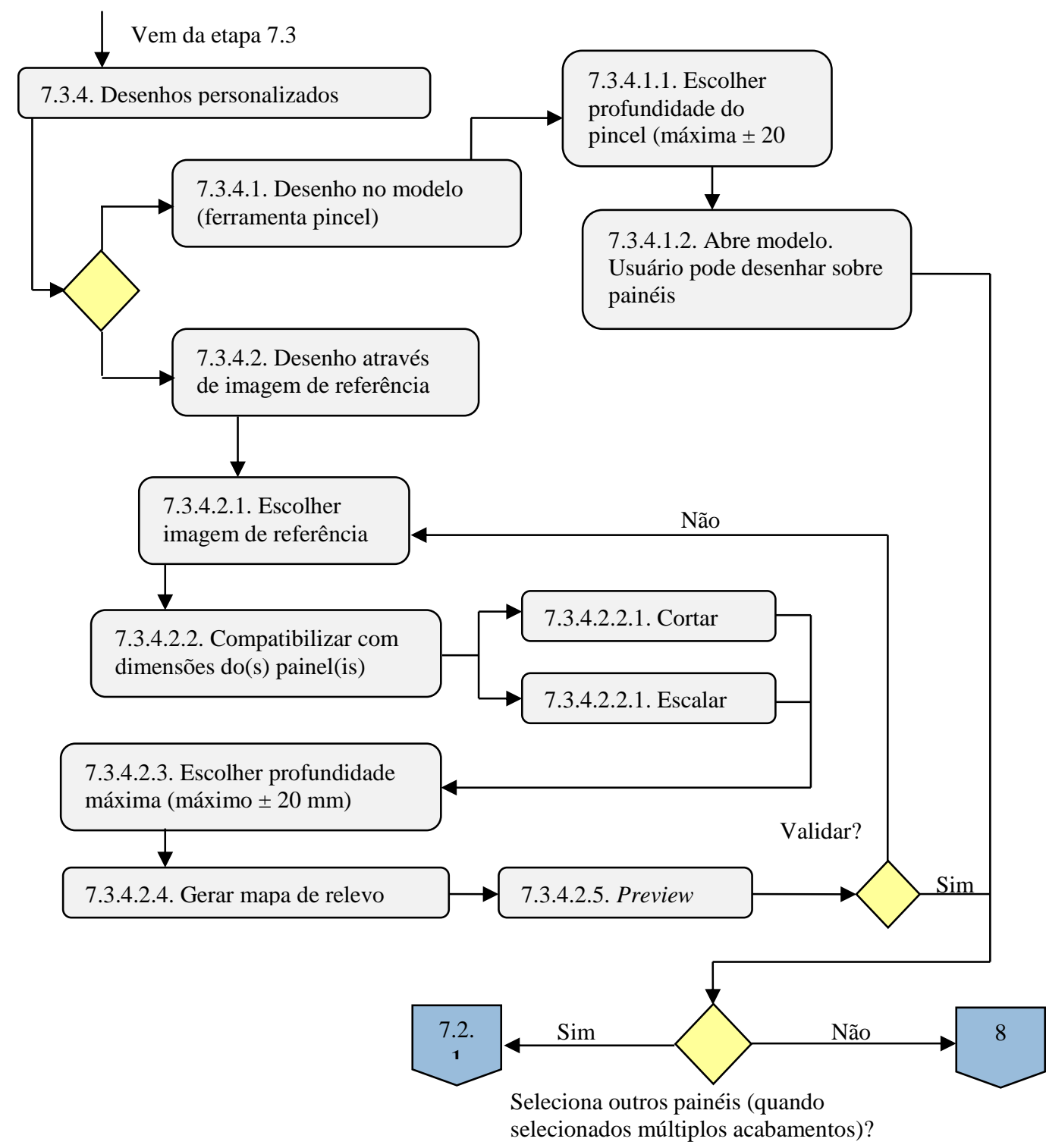

Figura 12 - Galpão utilizado como exemplo para simulação

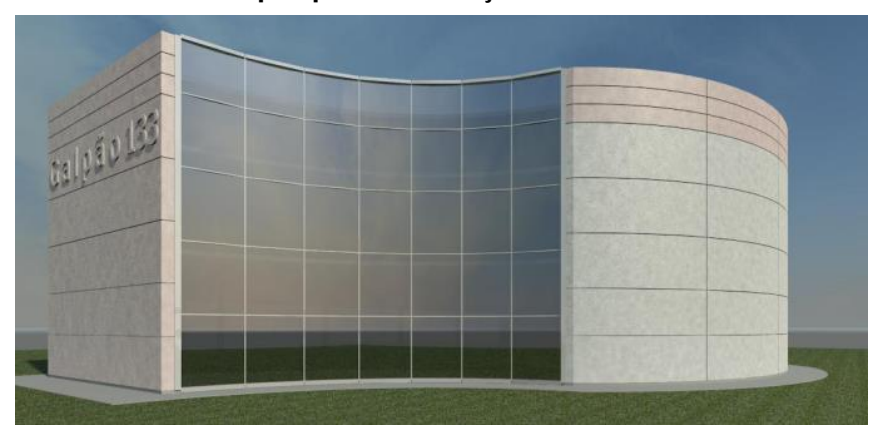


Figura 13 - Exemplo de simulação da edição da malha para os painéis

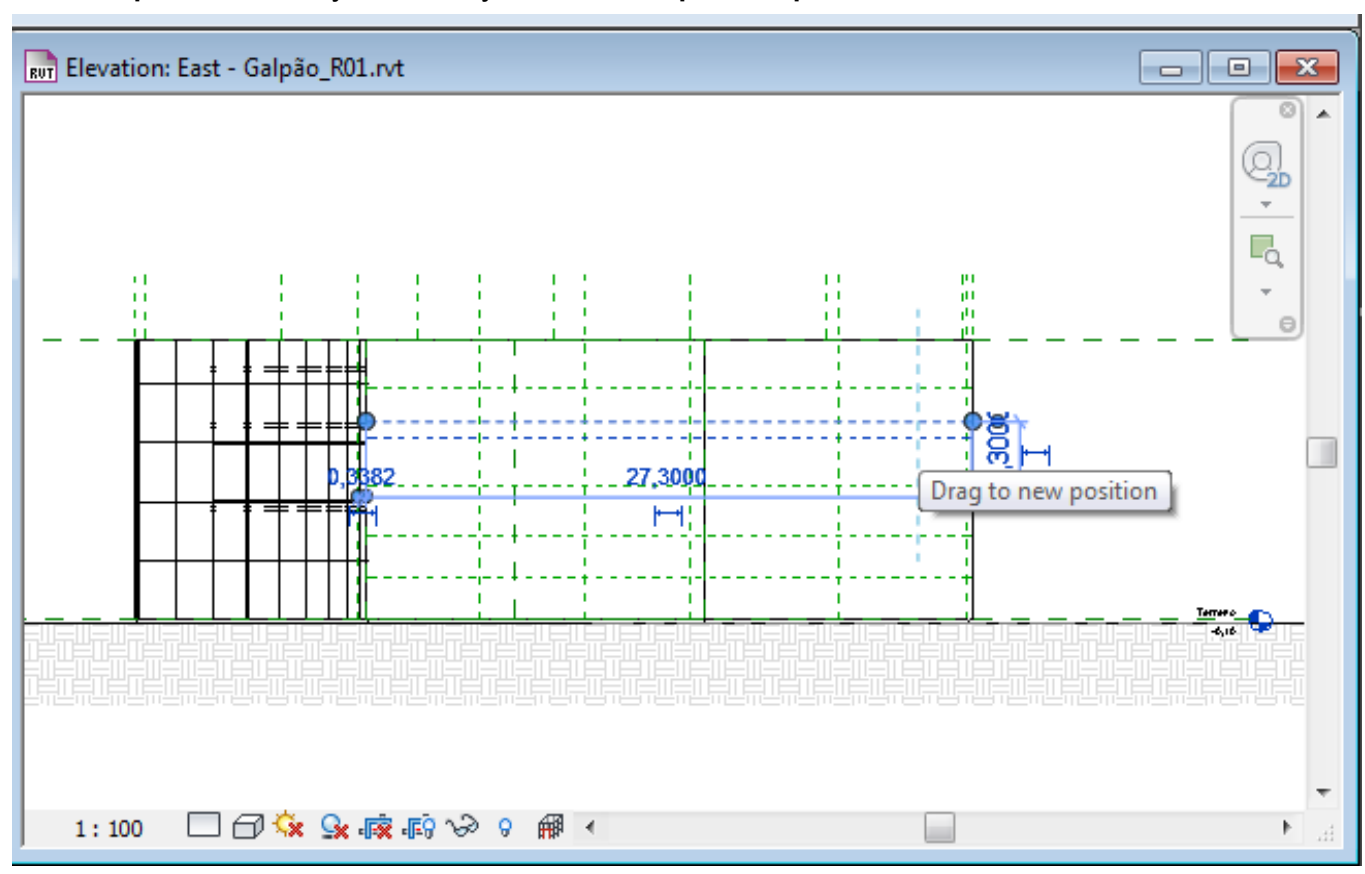

Após a indicação da modulação, simulou-se a indicação dos elementos de fixação (etapa 4) nos painéis. Para tanto, utilizou-se o recurso model lines e criou-se um elemento bidimensional, que representaria os insertos. Essa definição provou-se problemática para a exportação do modelo em IFC. Desse modo, a utilização de um elemento tridimensional é mais adequada (EL DEBS, 2013). Durante a simulação, a localização dos insertos foi feita manualmente em apenas alguns painéis.

Após a definição dos insertos, utilizou-se a ferramenta de estrutura (pilares) do Revit para indicar a localização proposta para os pilares de apoio para a estrutura (etapa de demarcação da pré-estrutura). Para esse galpão, assumiu-se a ligação dos painéis na estrutura através apenas de pilares. A Figura 14 representa a ilustração dos eixos de localização. Nota-se que o centro dos pilares está localizado, a princípio, entre os painéis. Nesta etapa é importante a avaliação crítica dos projetistas, para verificar se esse posicionamento é o mais adequado e, caso necessário, fazer o deslocamento do pilar após a conclusão do processo. No Revit, esses elementos foram projetados como elementos estruturais tridimensionais da ferramenta structure.
Pela simulação, a definição do formato das bordas dos painéis será uma informação não geométrica. Essa escolha foi feita para não sobrecarregar o modelo. Ela ficará armazenada dentro do elemento painel e deverá ser acessada no momento da fabricação. Tal característica poderá ser alterada em cada instância, depois que o processo de definição inicial seja finalizado. O projetista deverá escolher entre as opções ilustradas pela Figura 15. A largura das juntas é baseada na equação 1. Para a simulação, optou-se por juntas de $15 \mathrm{~mm}$, ligeiramente mais largas que o sugerido pela equação, que era de 13,044 $\mathrm{mm}$.

$\mathrm{O}$ elemento curtain grid do Revit também serviu para a criação de juntas falsas na faixa superior de painéis do galpão. Porém, a ferramenta reveal mostrou-se mais adequada à criação de frisos do que a utilizada originalmente na simulação.

Os acabamentos dos painéis (etapa 7) foram feitos mediante a escolha de materiais diferentes da biblioteca de acabamentos do Revit. A Figura 16 representa a visualização do modelo com a aplicação dos materiais. 
Figura 14 - Proposta da estrutura gerada para o galpão e vista 3D

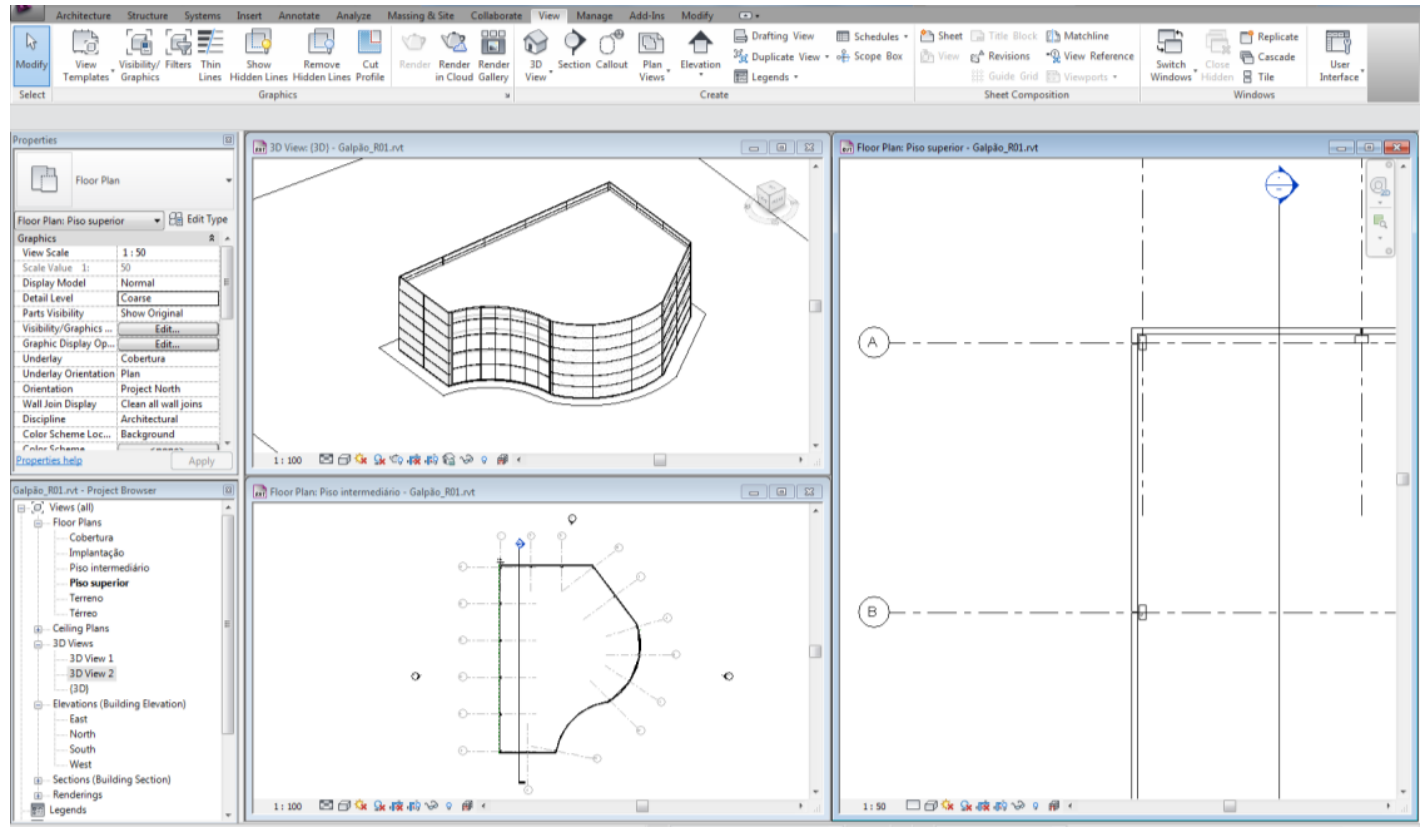

Figura 15 - Proposta da estrutura gerada para o galpão e vista 3D

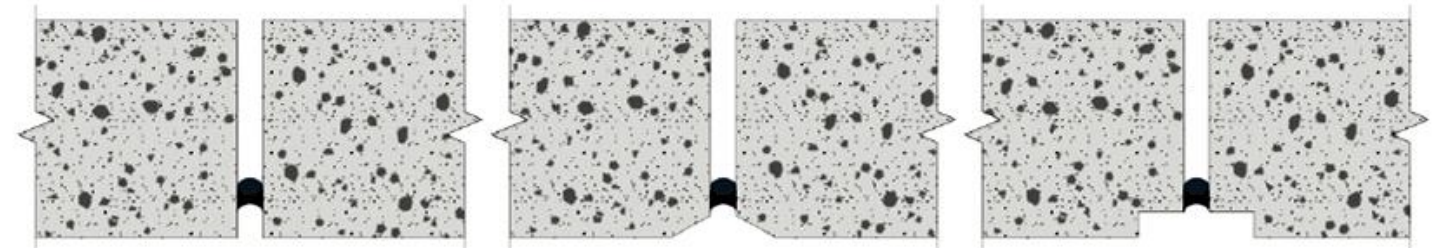

Fonte: Arantes (2009).

Figura 16 - Fachada do galpão em PPAC - acabamentos

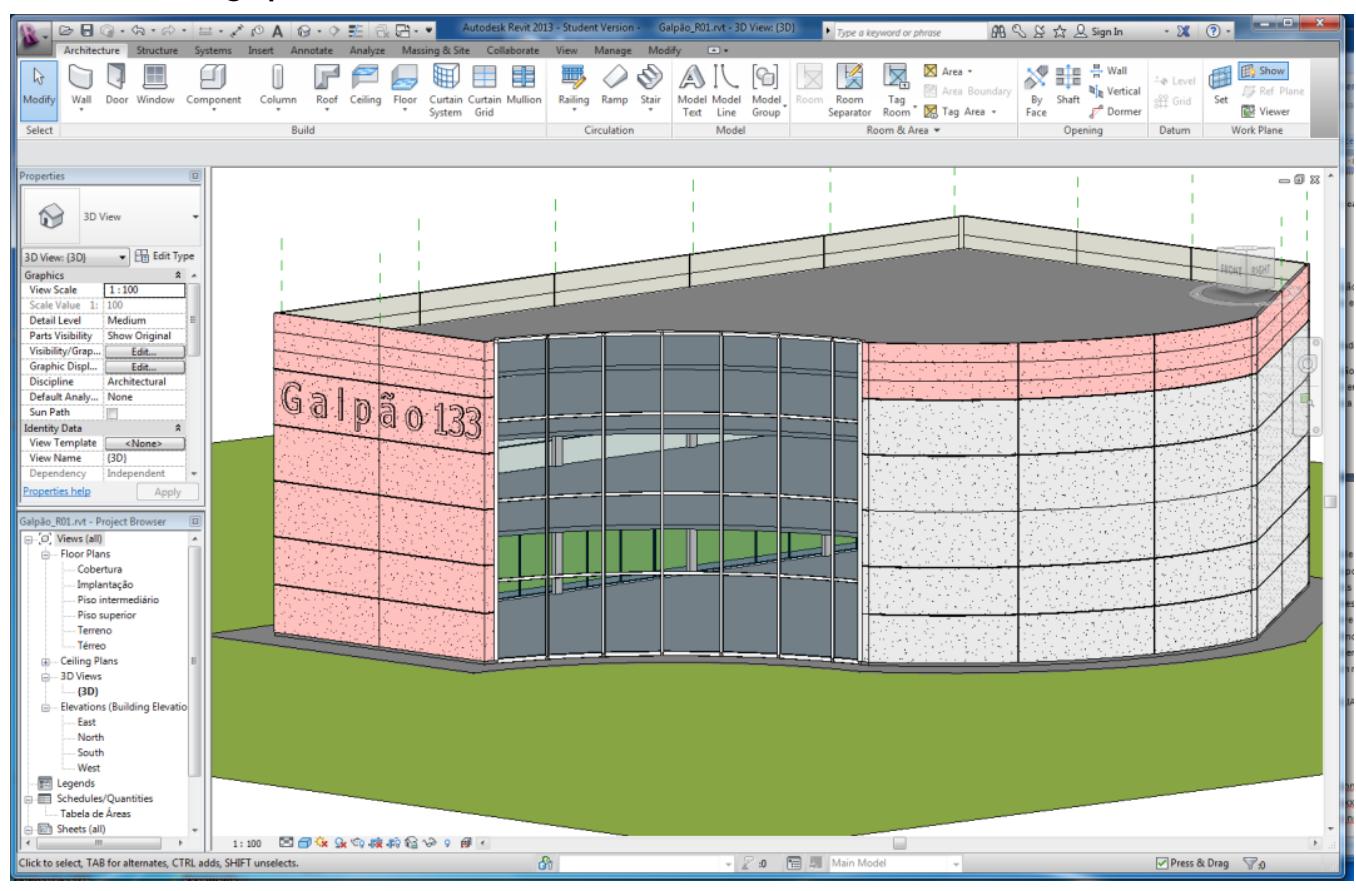


É também possível no Revit a aplicação de uma imagem nas paredes e a criação de letras em relevo. Essas ferramentas poderiam ser incorporadas para a aplicação dos conceitos relatados neste artigo, referentes ao processo de projeto.

Finalmente, representando a etapa 8 , os peitoris foram simulados utilizando-se a ferramenta reveal, após a indicação das janelas na posição desejada, conforme a representação da Figura 17.

Diversos dados não geométricos são necessários para a elaboração do projeto de PPACs. Desse modo, propôs-se a criação de campos extras dentro do elemento curtain wall para acomodar as informações necessárias. Entre algumas das sugestões para inclusão são:
(a) fck;
(b) tipo de selante utilizado;
(c) orientações e especificações da durabilidade do selante utilizado;

(d) vida útil de projeto (VUP);

(e) requisito de desempenho;

(f) número do painel;

(g) data de fabricação;

(h) data de instalação;

(i) recomendações para manutenções preventivas; e

(j) histórico de manutenções preventivas.

A Figura 18 representa a indicação de algumas das sugestões dentro das propriedades do elemento criado para a representação do painel durante a simulação.

Desse modo, procura-se permitir que o modelo criado sirva não apenas para a fase de projeto e fabricação, mas também durante a utilização do edifício, provendo informações importantes aos responsáveis por sua manutenção.

\section{Figura 17 - Indicação dos peitoris nas janelas}

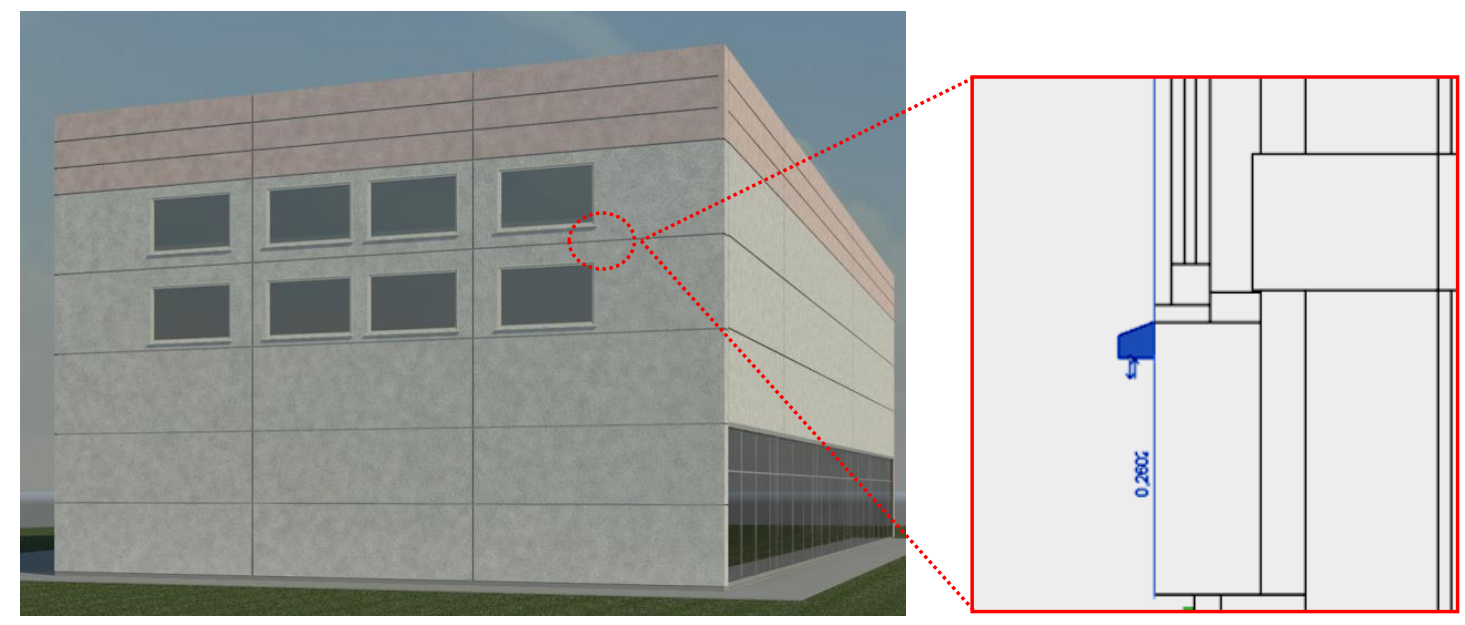

Figura 18 - Propriedades configuradas (a partir do fck) para o elemento PPAC, dentro do Revit

\begin{tabular}{|l|l|l|}
\hline Assembly Description & \\
\hline Assembly Code & \\
\hline Type Mark & \\
\hline Fire Rating & \\
\hline Cost & \\
\hline fck & \\
\hline Tipo de selante utilizado & \\
\hline Orientações sobre durabilidade do selante & \\
\hline Vida Útil de Projeto (VUP) & \\
\hline Requisito de desempenho & \\
\hline Recomendações para manutenções preventivas & \\
\hline
\end{tabular}


Após a simulação, foi realizado um balanço sobre as dificuldades. Foi necessária a revisão de alguns fluxogramas para adequar a sequência de projeto à utilização das ferramentas disponíveis no aplicativo. Os diagramas apresentados no item anterior já contemplam essa alteração. De modo geral, o modelador Revit possui as ferramentas necessárias para o desenvolvimento do processo, sendo necessário o desenvolvimento de programação específica que as utilize de acordo com o processo proposto. Nesta etapa, mais dificuldades e limitações podem ser detectadas. Essas questões deverão se analisadas, para permitir o aperfeiçoamento da proposta com o tempo e de acordo com as necessidades e solicitações dos interessados em sua utilização.

\section{Principais características do BIM que podem ser aproveitadas no processo proposto}

Como apresentado neste artigo, o processo proposto possui oito etapas principais, que permitem a definição das características dos PPACs. Ele surge também como agente facilitador à especificação do sistema e permite ao usuário mais familiaridade com alguns termos técnicos. Procurou-se, com a proposta, abranger a maior parte de características indicadas pelos estudos teóricos e entrevistas. O Quadro 2 apresenta o relacionamento das características apresentadas e algumas propostas pelos entrevistados, e as que foram abordadas em cada fase da proposta. Nela também é possível verificar se os dados fornecidos pelos itens serão geométricos, não geométricos, ou de ambos os tipos.

Também foi realizada a análise de classes e variáveis do modelo IFC que podem ser utilizadas durante as etapas de projeto. Essa relação é apresentada no Quadro 3 e tem com objetivo orientar a exportação do modelo BIM criado em aplicativo proprietário para o modelo aberto (IFC).

Quadro 2 - Características abordadas pelo processo proposto

\begin{tabular}{|c|c|c|c|c|}
\hline \multirow[b]{2}{*}{ Característica } & \multirow{2}{*}{$\begin{array}{c}\text { Característica } \\
\text { indicada como } \\
\text { principal }\end{array}$} & \multirow{2}{*}{$\begin{array}{c}\text { Item } \\
\text { correspondente } \\
\text { do processo }\end{array}$} & \multicolumn{2}{|c|}{ Dados } \\
\hline & & & Geométrico & $\begin{array}{c}\text { Não } \\
\text { geométrico }\end{array}$ \\
\hline Dimensões & Sim & $\begin{array}{l}\text { Item } 1 / \text { Item } \\
2 / \text { Item } 3\end{array}$ & $\mathrm{X}$ & \\
\hline $\begin{array}{l}\text { Existência e especificação de isolamento } \\
\text { (acústico ou térmico) }\end{array}$ & Sim & Item 2 & $\mathrm{X}$ & $\mathrm{X}$ \\
\hline Cor do painel & Sim & Item 7 & & $\mathrm{X}$ \\
\hline Textura do painel (lisa, áspera, desenhada...) & Sim & Item 7 & & $\mathrm{X}$ \\
\hline Localização das ligações/insertos metálicos & Sim & Item 4 & $\mathrm{X}$ & \\
\hline Especificação das ligações/insertos metálicos & Não & Item 4 & $\mathrm{X}$ & $\mathrm{X}$ \\
\hline $\begin{array}{l}\text { Indicação do tipo de inserto/ligação (gravidade, } \\
\text { alinhamento ou contraventamento) }\end{array}$ & Não & Item 4 & & $\mathrm{X}$ \\
\hline Indicação das juntas falsas & Sim & Item 6 & $\mathrm{X}$ & \\
\hline Largura das juntas verdadeiras & Sim & Item 5 & $\mathrm{X}$ & \\
\hline Indicação de juntas de um ou dois estágios & Sim & Item 5 & & $\mathrm{X}$ \\
\hline Detalhamento de quinas, evitando $90^{\circ}$ & Sim & Item $5^{1}$ & $\mathrm{X}$ & \\
\hline $\begin{array}{l}\text { Especificação da resistência do concreto a ser } \\
\text { utilizado }\end{array}$ & Não & \multicolumn{3}{|c|}{ Não abordada } \\
\hline Indicação do peso do painel & Sim & & $\mathrm{X}$ & $\mathrm{X}$ \\
\hline Localização sugerida para as alças de içamento & Não & \multicolumn{3}{|c|}{ Não abordada } \\
\hline Indicação das juntas corta-fogo & Não & Item 5 & & $\mathrm{X}$ \\
\hline $\begin{array}{l}\text { Interface e compatibilidade entre os } \\
\text { subsistemas da obra }\end{array}$ & Não & \multicolumn{3}{|c|}{ Não abordada } \\
\hline $\begin{array}{l}\text { Adequação da linguagem arquitetônica à } \\
\text { tecnologia }\end{array}$ & Não & \multicolumn{3}{|c|}{ Não abordada diretamente } \\
\hline Cálculo de isolamento térmico & Não & \multicolumn{3}{|c|}{ Não abordada } \\
\hline $\begin{array}{l}\text { Indicação das aberturas (para caixilhos) } \\
\text { conforme modulação dos painéis }\end{array}$ & Não & \multicolumn{3}{|c|}{ Não abordada diretamente } \\
\hline
\end{tabular}

Nota: 1 - Optou-se por deixar a indicação de quina a $90^{\circ}$ como alternativa, porém fazendo um alerta ao usuário de que essas quinas podem sofrer quebras. 
Quadro 3 - Classes e variáveis do modelo IFC que estruturam as informações necessárias ao processo, identificadas durante a simulação

\begin{tabular}{|c|c|}
\hline Característica do processo & No modelo IFC \\
\hline Dimensões & IfcShapeRepresentation \\
\hline \multirow[b]{2}{*}{$\begin{array}{l}\text { Existência e especificação de isolamento } \\
\text { (acústico ou térmico) }\end{array}$} & IfcShapeRepresentation \\
\hline & $\begin{array}{l}\text { IfcRelDefinesByProperties } \\
\text { Pset_CurtainWallCommon: } \\
\text { - AcousticRating } \\
\text { - ThermalTransmittance }\end{array}$ \\
\hline Cor do painel & IfcMaterialDefinitionRepresentation \\
\hline Textura do painel (lisa, áspera, desenhada...) & IfcMaterialDefinitionRepresentation \\
\hline $\begin{array}{l}\text { Localização das ligações / insertos } \\
\text { metálicos }\end{array}$ & IfcLocalPlacement \\
\hline \multirow{2}{*}{$\begin{array}{l}\text { Especificação das ligações/insertos } \\
\text { metálicos }\end{array}$} & IfcShapeRepresentation \\
\hline & IfcRelConnectsElements \\
\hline $\begin{array}{l}\text { Indicação do tipo de inserto/ligação } \\
\text { (gravidade, alinhamento, contraventamento) }\end{array}$ & IfcRelDefinesByProperties \\
\hline Indicação das juntas falsas & $\begin{array}{l}\text { IfcLocalPlacement } \\
\text { IfcShapeRepresentation }\end{array}$ \\
\hline Largura das juntas verdadeiras & $\begin{array}{l}\text { IfcLocalPlacement } \\
\text { IfcShapeRepresentation }\end{array}$ \\
\hline Indicação de juntas de um ou dois estágios & IfcRelDefinesByProperties \\
\hline Detalhamento de quinas, evitando $90^{\circ}$ & IfcShapeRepresentation \\
\hline \multirow[b]{2}{*}{ Indicação do peso do painel } & Pset_MaterialCommon \\
\hline & $\begin{array}{cl}\text { Qto_CurtainWallQuantities } \\
\text { - } & \text { Length } \\
\text { - } & \text { Heigth } \\
\text { - } & \text { Width }\end{array}$ \\
\hline Indicação das juntas corta-fogo & IfcRelDefinesByProperties \\
\hline
\end{tabular}

A utilização de um modelo BIM, nesse caso, permite que diversas informações necessárias para a especificação de elementos PPACs sejam para ele transferidos através do processo proposto e, futuramente, através de uma ferramenta interna ao modelador. As etapas do processo proposto resultam em diversas informações geométricas e não geométricas, que alimentam o modelo BIM. Este, por sua vez, se beneficia de regras paramétricas, além do armazenamento de dados geométricos e não geométricos, para conter as informações necessárias ao projeto em um menor número de arquivos. A modelagem tridimensional permite a visualização de erros em etapas anteriores de projeto, se comparado ao processo tradicional em duas dimensões. Isso auxilia a realização de projetos com menos erros e mais adequados ao uso de elementos pré-fabricados.

\section{Considerações finais e conclusões}

O trabalho propôs a organização de características ligadas ao elemento PPAC mediante um processo de projeto que se beneficia da modelagem BIM, tendo em vista a similaridade da lógica de montagem presente em ambos - elementos préfabricados e Building Information Modeling.

Os estudos realizados indicam que 13 das 19 características apontadas por especialistas como principais para o desenvolvimento de projetos que utilizam o elemento PPAC foram abordadas no processo proposto, contabilizando $68 \%$. Foi possível realizar a simulação do processo, que é composto de oito etapas, organizadas em fluxogramas, dentro do aplicativo Revit. Também foi possível simular a criação dos painéis (etapa 3, baseada em informações das etapas 1 e 2), insertos (etapa 4), juntas (etapas 5 e 6), acabamentos (etapa 7) e os peitoris (etapa 8, parcialmente). O modelo gerado foi exportado em IFC, o que demonstrou que a proposta pode se beneficiar da interoperabilidade entre aplicativos. Dessa forma, procurou-se realizar um mapeamento do processo de projeto, organizado em fluxogramas e testado com os recursos de modelagem disponíveis em uma ferramenta existente (Revit), resultando na validação da proposta para o futuro desenvolvimento de uma ferramenta computacional. 
Entende-se que a utilização do BIM seja benéfica para o estímulo da utilização de elementos préfabricados na construção brasileira, pois ele leva à elaboração de projetos com menos erros e mais adequado à pré-fabricação da construção. Essa intenção está de acordo com os achados dos estudos teóricos internacionais apresentados no início do texto (KANER et al., 2008; SACKS et al., 2005; EASTMAN et al., 2008; JEONG et al., 2009). Os trabalhos teóricos nacionais utilizados como referência indicam as características dos PPACs, mas não necessariamente um fluxo de trabalho. Este trabalho procura suprir essa falta, além de inseri-lo dentro de um ambiente BIM.

A concepção do processo proposto para a criação dos painéis não elimina nem diminui a importância do diálogo de projetista com fabricantes e construtores, mas, sim, intensifica e facilita a interação. Isso ocorre porque os projetistas podem verificar visualmente as consequências das escolhas e definições de fabricação e de construção tomadas, além de compreender as consequências das definições de etapas anteriores para o resultado final.

A vantagem de se utilizar o ambiente BIM para o processo está de acordo com os estudos internacionais para maior utilização desse processo. Além disso, alguns desses estudos indicam ganho significativo em produtividade $\mathrm{e}$ diminuição de erros em projetos de elementos préfabricados desenvolvidos através do Building Information Modeling.

Apresenta-se como principal limitação deste trabalho a falta de teste do processo em uma obra real. Os testes prévios realizados foram criteriosos e apontaram diversas melhorias. Como sugestão para futuros trabalhos, tem-se:

(a) o desenvolvimento da ferramenta que utilize esse processo dentro dos modeladores e a verificação com o teste em uma obra real de sua efetividade para a difusão desse elemento no mercado da construção brasileiro;

(b) e a elaboração de processos de projeto como o proposto para outros elementos pré-fabricados.

\section{Referências}

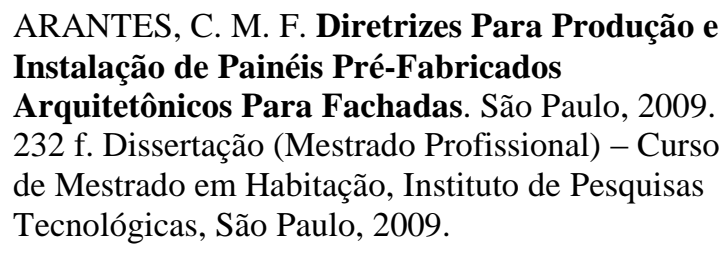

BRUNA, P. J. V. Arquitetura, Industrialização e Desenvolvimento. 2. ed. São Paulo: Perspectiva, 2002. 307 p. (Debates).

CERVO, A. L.; BERVIAN, P. A. Metodologia

Científica. 4. ed. São Paulo: Makron Books, 1996.

EASTMAN, C. M. et al. Building Information

Modeling (BIM) For Precast Architectural

Concrete. Atlanta: Charles Pankow Foundation, 2008.

EASTMAN, C. et al. Bim Handbook: a guide to building information modeling for owners, managers, designers, engineers, and contractors. $2^{\text {nd }}$ ed. Hoboken: John Wiley \& Sons, 2011.

\section{EL DEBS, L. C. Proposta de Ferramenta}

Computacional BIM Para Auxílio ao Projeto de Fachadas em Painéis Pré-Fabricados

Arquitetônicos de Concreto. São Paulo, 2013. 200 f. Dissertação (Mestrado Profissional) - Curso de Mestrado em Habitação, Instituto de Pesquisas Tecnológicas, São Paulo, 2013.

\section{EL DEBS, M. K. Concreto Pré-Moldado:} fundamentos e aplicações. São Carlos: EESC-USP, 2000.

FERREIRA, S. L.; KAWANO, A. Proposta de Ampliação do Modelo IFC Com a Contribuição do IES LM-63: a luminária no ciclo de vida da edificação. São Paulo: Epusp, 2006. Boletim Técnico da Escola Politécnica da USP.

GIL, A. C. Como Elaborar Projetos de Pesquisa. São Paulo: Atlas, 2002.

INTERNATIONAL ORGANIZATION OF STANDARDIZATION. ISO 16739: Industry Foundation Classes (IFC) for data sharing in the construction and facility management industries. London, 2013.

JEONG, Y-S. et al. Benchmark Tests For BIM Data Exchanges of Precast Concrete. Automation in Construction, Oxford, v. 18, n. 5, p. 469-484, aug. 2009.

KANER, I. et al. Case Studies of BIM Adoption For Precast Concrete Design by Mid-Sized Structural Engineering Firms. ITcon, v. 13, edição especial, p. 303-323, jun. 2008.

OLIVEIRA, L. A. de. Tecnologia de Painéis PréFabricados de Concreto Para Emprego em Fachadas de Edifícios. São Paulo, 2002. 175 f. Dissertação (Mestrado em Engenharia Civil) Departamento de Escola Politécnica, Universidade de São Paulo, São Paulo, 2002.

ORDONÉZ, J. A. F. Prefabricación: teoria y práctica. Barcelona: Editores Técnicos Associados, 1974. v. 1. 
PRECAST; PRESTRESSED CONCRETO

INSTITUTE (Eds.). Architectural Precast

Concrete Manual. $3^{\text {th }}$. ed. Chicago: Precast, Prestressed Concrete Institute, 2007.

SABBATINI, F. H.; OLIVEIRA, L. A.;

MELHADO, S. B. O Papel Estratégico do Projeto Para a Qualidade dos Painéis Pré-Fabricados de Fachada. In: SIMPÓSIO BRASILEIRO DE QUALIDADE DO AMBIENTE CONSTRUÍDO, 2., Fortaleza, 2001. Anais... Fortaleza, 2001
SACKS, R. et al. A Target Benchmark of the Impact of Three-Dimensional Parametric Modeling in Precast Construction. Journal of the Precast, v. 50, p. 126-139, jul./aug. 2005.

\section{SMITH, D. K.; TARDIF, M. Building}

Information Modeling: a strategic implementation guide for architects, engineers, constructors, and real estate asset managers. Hoboken: John Wiley \& Sons, 2009.

\section{Revista Ambiente Construído}

Associação Nacional de Tecnologia do Ambiente Construído

Av. Osvaldo Aranha, $99-3^{\circ}$ andar, Centro

Porto Alegre - RS - Brasil

CEP $90035-190$

Telefone: +55 (51) 3308-4084

Fax: +55 (51) 3308-4054

www.seer.ufrgs.br/ambienteconstruido

E-mail: ambienteconstruido@ufrgs.br 